\title{
Study pada ZigBee Protocol
}

\author{
Nurhayati a , dan Muhammad Hasrul Ma'ruf ${ }^{\text {b }}$ \\ ${ }^{a), b)}$ Dosen Program Studi Teknik Informatika \\ Fakultas Sains dan Teknologi \\ Universitas Islam Negeri Syarif Hidayatullah Jakarta \\ e-mail:nurhayatibuslim@gmail.com,hasrulwho@gmail.com
}

\begin{abstract}
Nowadays, Technology is growing rapidly, the one of example of technology, helps the human being to fulfill their need of information. The development of information technology and communication make the data faster and also make the updating data easier for example protocols. The used of information and communication technology that is simple, automatic, low rate data and the lasting power has become imperative in accordance with technological developments. In the field of wireless networking technology networks currently well addressed for this include Zigbee protocol. The technology in the specified ZigBee aimed at them. ZigBee is a specification for high-level communication protocol package that uses a small amount of low-power digital radios based on, the IEEE 802.15.4 standard for wireless personal area networks (WPANs). In this paper we discuss further on what and how Zigbee is, how the relationship the IEEE and Zigbee are, who uses of Zigbee, how history of Zigbee is. What the hardware and software on Zigbee are, how it work as well as the type of Zigbee does. What the types of applications that use Zegbee are and how usability Zigbe in general and home applications is.
\end{abstract}

Keywords: Wireless Personal Area networks (WPAN)s, IEEE, Zigbee.

\section{PENDAHULUAN}

Meningkatnya kebutuhan di bidang Teknologi informasi dan komunikasi sejalan dengan perkembangan IT yang begitu pesatnya. Setiap saat selalu bermunculan alat-alat elektronik yang menggunakan teknologi yang up-to-date. Salah satunya adalah teknologi di bidang protocol pada jaringan nirkabel.

Di mana teknologi ZigBee adalah sebuah spesifikasi untuk paket protokol komunikasi tingkat tinggi yang menggunakan sejumlah kecil radio digital daya rendah yang didasarkan pada, Standard IEEE 802.15.4 untuk jaringan nirkabel wilayah pribadi (WPANs), seperti headphone nirkabel menghubungkan dengan ponsel melalui radio jarak pendek.

IEEE adalah Institute of Electrical and Electronics Engineers. Mereka adalah organisasi nonprofit yang didedikasikan untuk memajukan teknologi yang melibatkan elektronik dan perangkat elektronik. Kelompok 802 adalah bagian dari IEEE yang terlibat dalam operasi jaringan dan teknologi, termasuk jaringan menengah dan jaringan lokal. Kelompok 15 penawaran khusus dengan teknologi jaringan nirkabel, dan termasuk kelompok 802.15.1 sekarang yang juga dikenal sebagai Bluetooth. Teknologi yang didefinisikan oleh spesifikasi ZigBee ditujukan untuk menjadi sederhana dan lebih murah dibandingkan WPANs lain, seperti Bluetooth. ZigBee ditargetkan pada frekuensi radio (RF) aplikasi yang memerlukan rate data yang rendah,baterai yang tahan lama, dan jaringan yang aman.

\section{LANDASAN TEORI}

\subsection{Definisi Zigbee}

Berdasar penjelasan dan definisi sebelumnya kita ketahui ZigBee adalah sebuah jaringan nirkabel standar "Mesh" yang berbiaya-rendah, daya rendah. Biaya rendah memungkinkan teknologi untuk digunakan secara luas dalam nirkabel kontrol dan aplikasi pemantauan, penggunaan daya rendah memungkinkan waktu hidup lebih lama dengan baterai yang lebih kecil, dan jaringan "Mesh" memberikan keandalan tinggi dan jangkauan yang lebih besar. Sebagai suatu protocol pada sebuah jaringan nirkabel memiliki standar ZigBee Alliance.

ZigBee Alliance, adalah badan standar yang mendefinisikan ZigBee, juga menerbitkan profil 
aplikasi yang memungkinkan beberapa vendor OEM untuk menciptakan produk interoperable. Saat ini profil daftar aplikasi yang sudah diterbitkan diantaranya adalah:

a. Peralatan otomatis untuk rumah;

b. ZigBee Smart Energi;

c. Aplikasi Telekomunikasi;

d. Kebutuhan pribadi rumah tangga

e. Peralatan rumah sakit.

Sebagai suatu protocol Zegbe memiliki keterkaitan dengan IEEE, yakni tepatnya hubungan antara IEEE 802.15.4 dan ZigBee adalah serupa dengan hubungan antara IEEE 802.11 dan Wi-Fi Alliance. ZigBee 1.0 spesifikasi disahkan pada tanggal 14 Desember 2004 dan tersedia untuk anggota ZigBee Alliance. Selanjutnya spesifikasi ZigBee 2007 diposting pada tanggal 30 Oktober 2007. ZigBee pertama adalah profil aplikasi untuk peralatan rumah tangga otomatis, diumumkan 2 November 2007.

Selain dengan tujuan komersial terdapat juga yang non komersial. Untuk tujuan non-komersial, spesifikasi ZigBee tersedia gratis untuk masyarakat umum. Masuk ke dalam tingkat keanggotaan dalam sebuah Aliansi ZigBee, disebut adopter, dengan biaya US \$ 3500 per tahun dan menyediakan akses ke spesifikasi yang belum dipublikasikan dan izin untuk menciptakan produk-produk untuk pasar menggunakan spesifikasi tersebut. Untuk ZigBee yang beroperasi di bidang industri, ilmiah dan medis (ISM) band-band radio; $868 \mathrm{MHz}$ di Eropa, $915 \mathrm{MHz}$ di negara-negara seperti Amerika Serikat dan Australia, dan 2,4 GHz di sebagian besar wilayah yurisdiksi di seluruh dunia. Teknologi ini dimaksudkan untuk menjadi sederhana dan lebih murah dibandingkan WPANs lain seperti Bluetooth. Vendor chip ZigBee biasanya menjual radio terintegrasi dengan Microcontrollers antara 60k dan 128K memori flash, seperti Freescale MC13213, yang EM250 Ember dan Texas Instruments CC2430. Radio juga tersedia yang berdiri sendiri untuk digunakan dengan prosesor atau mikrokontroler. Secara umum, vendor chip juga menawarkan perangkat lunak ZigBee tumpukan, meskipun yang berdiri sendiri juga tersedia.

Pada tahun 2006, harga eceran sebuah transceiver ZigBee-compliant mendekati \$ 1, dan harga untuk paket satu radio, prosesor, dan memori adalah sekitar \$ 3. Harga relatif konsumen kelas chip Bluetooth sekarang berada di bawah $\$ 3$. Rilis tumpukan pertama sekarang disebut ZigBee 2004. Rilis tumpukan kedua disebut ZigBee 2006, dan terutama menggantikan struktur MSG / KVP digunakan pada tahun 2004 dengan sebuah "cluster library ". Model Tumpukan 2004 sekarang dianggap sudah usang.

Saat ini ZigBee 2007 yang dirilis memiliki model tumpukan yakni berisi: bentuk 2 tumpukan, bentuk 1 tumpukan (hanya disebut ZigBee) untuk rumah dan penggunaan cahaya komersial, dan bentuk 2 tumpukan (disebut ZigBee Pro). ZigBee Pro menawarkan lebih banyak fitur, seperti multi-casting, banyak-ke-satu routing dan keamanan yang tinggi dengan Symmetric-Key Key Exchange (SKKE), sementara ZigBee (bentuk 1 tumpukan) menawarkan ruang yang sangat kecil dalam RAM dan flash. Keduanya menawarkan menyeluruh jaringan mesh dan bekerja dengan semua bentuk aplikasi ZigBee. ZigBee 2007 adalah sepenuhnya kompatibel dengan perangkat ZigBee 2006: sebuah perangkat ZigBee dapat bergabung 2007 dan beroperasi pada jaringan ZigBee 2006 dan sebaliknya. Karena perbedaan dalam pilihan routing, Pro ZigBee perangkat harus menjadi non-routing-ZigBee End Devices (ZEDs) pada ZigBee 2006 atau ZigBee 2007 jaringan, sama seperti ZigBee 2006 atau 2007 ZigBee perangkat harus menjadi ZEDs pada jaringan Pro ZigBee. Aplikasi yang berjalan pada perangkat tersebut bekerja sama terlepas dari profil tumpukan yang berada di bawah mereka..

\subsection{Sejarah asal mula nama Zigbee}

Suatu istilah tentu ada asal mulanya. Demikian pula dengan Zigbee ini, agar lebih jelas dari mana istilah ini muncul serta apa kegunaannya yang sebenarnya. Untuk itu hal menarik juga untuk kita pelajari adalah asal nama Zigbee. Pada awalnya nama "ZigBee" berasal dari pola zigging menentu banyak lebah membuat antara bunga ketika mengumpulkan serbuk sari. inilah menjadi ide pada jaring yang tidak kelihatan dari koneksi yang ada dalam lingkungan yang sepenuhnya nirkabel. Standar itu sendiri diatur oleh sebuah kelompok yang dikenal sebagai ZigBee Alliance, dengan lebih dari 150 anggota di seluruh dunia. Artikel yang dipublikasikan oleh organisasi berita teknologi seperti pada EDN dan Telekomunikasi Online mengklaim bahwa istilah "ZigBee" berasal dari zig-zag goyangan tarian lebah madu digunakan untuk berbagi informasi penting, seperti lokasi, jarak, dan arah sumber makanan yang baru ditemukan, dengan sarang sesama anggota. Meshnetics produsen perangkat ZigBee mengacu pada sistem komunikasi ini sebagai "Prinsip ZigBee" Namun,. Tidak ada istilah baku tersebut di apiology, 
studi ilmiah lebah madu. Robert Metcalfe, penemu Ethernet dan seorang pekerja pada pengembangan awal pada ZigBee, dikonfirmasi wartawan pada tahun 2004 bahwa nama awalnya berarti dan telah dipilih dari daftar panjang atas dasar bahwa itu merupakan kewajiban terhadap suatu merek dagang yang belum ada, sehingga harus di beri nama dan nama tersebut bisa di gunakan.

Untuk itu baiknya kita mempelajari sejarah Zigbee agar bisa memahami lebih jelas lagi asal mulanya serta segala hal yang berkaitan dengannya. Sejarah Zigbee berawal dari adanya:

a. Gaya Jaringan ZigBee mulai dipahami tentang tahun 1998, ketika banyak installer menyadari bahwa baik WiFi dan Bluetooth yang akan cocok untuk banyak aplikasi. Secara khusus, banyak insinyur melihat kebutuhan untuk mengorganisir diri jaringan ad-hoc radio digital.

b. IEEE 802.15.4 standar selesai pada Mei 2003.

c. Pada musim panas tahun 2003, Philips Semikonduktor, pendukung jaringan mesh, berhenti investasi. Philips Lighting, bagaimanapun terus berpartisipasi dan Philips sebagai anggota tetap promotor di Dewan Direksi ZigBee Alliance.

d. ZigBee Alliance mengumumkan pada Oktober 2004 bahwa keanggotaan memiliki lebih dari dua kali lipat pada tahun sebelumnya dan telah berkembang menjadi lebih dari 100 perusahaan anggota, di 22 negara. Pada April 2005 keanggotaan telah berkembang menjadi lebih dari 150 perusahaan, dan pada bulan Desember 2005 anggota telah melewati 200 perusahaan.

e. Spesifikasi ZigBee diratifikasi pada tanggal 14 Desember 2004.

f. ZigBee Alliance mengumumkan ketersediaan umum Spesifikasi 1.0 pada 13 Juni 2005, dikenal sebagai ZigBee 2004 Spesifikasi.

g. ZigBee Alliance mengumumkan penyelesaian dan ketersediaan anggota langsung dari versi yang disempurnakan dari ZigBee Standar pada bulan September 2006, dikenal sebagai ZigBee 2006 Spesifikasi.

h. Selama kuartal terakhir 2007, ZigBee PRO, ditingkatkan dari ZigBee Spesifikasi yang diselesaikan.

\subsection{Tujuan Zigbee}

Protokol ZigBee ditujukan untuk digunakan dalam embedded aplikasi yang membutuhkan data berbiaya rendah dan mengkonsumsi daya rendah juga. Sehingga fokus ZigBee saat ini adalah untuk menentukan tujuan umum, murah, mengorganisir dalam jaringan mesh yang dapat digunakan untuk fungsi kontrol pada bidang industri, penginderaan, pengumpulan data medis, peringatan asap dan penyusupan, otomatisasi bangunan, otomatisasi rumah, dan lain-lain.

Jaringan akan menggunakan jumlah daya yang sangat kecil. Suatu perangkat individu harus memiliki baterai minimal dua tahun untuk lulus sertifikasi ZigBee.

Pemanfatan pada bidang aplikasi umum termasuk diantaranya adalah:

a. Dunia Hiburan dan Pengendalian - pencahayaan yg bagus, kontrol suhu yang baik, keselamatan dan keamanan, film dan musik.

b. Peralatan Rumah - sensor udara, sensor listrik, detektor asap dan api, peralatan cerdas dan sensor akses.

c. Mobile Services - m-pembayaran, m-monitoring dan kontrol, m-keamanan dan kontrol akses, mkesehatan dan tele-membantu.

d. Bangunan Komersial - Energi pemantauan, HVAC, pencahayaan, kontrol akses.

e. Industri Pabrik - Kontrol Proses, manajemen aset, manajemen lingkungan, manajemen energi, kontrol perangkat industri

\section{ZIGBEE}

\subsection{Perangkat Zigbee}

Saat ini ada tiga jenis perangkat pada ZigBee yakni :

1. ZigBee Coordinator (ZC): Alat yang paling mampu, berbentuk koordinator seperti akar pada jaringan pohon dan mungkin juga sebagai jembatan ke jaringan lain. Ada tepat satu koordinator di setiap jaringan ZigBee karena merupakan perangkat yang dimulai awalnya jaringan. Hal ini dapat menyimpan informasi tentang jaringan, termasuk bertindak sebagai Pusat Trust \& repositori untuk kunci keamanan.

2. ZigBee Router (ZR): Seperti halnya menjalankan fungsi aplikasi router dapat bertindak sebagai router antara, melewati data dari perangkat lain.

3. ZigBee End Device (ZED): Berisi fungsi cukup untuk berbicara dengan node induk (baik koordinator atau router), itu tidak bisa mengirim data dari perangkat lain. 
Hubungan ini memungkinkan node akan tertidur sejumlah besar waktu sehingga memberikan baterai yang tahan lama. Sebuah ZED membutuhkan paling sedikit memori, dan karenanya dapat lebih murah untuk memproduksi daripada ZR atau ZC.

\subsection{ZigBee Protocol}

Kelompok IEEE 802.15.4 baru-baru ini mengusulkan standar fisik (PHY) dan kontrol akses media (MAC) lapisan [1]. Wireless Personal Area Networks (WPAN) dioptimalkan untuk rendahnya tingkat aplikasi data (,01-250 kbit / s) dengan sederhana atau tidak ada kualitas layanan (QoS) persyaratan. IEEE 802.15.4 dirancang untuk interkoneksi nirkabel ultra rendah biaya sensor, aktuator, dan perangkat pengolahan, yang akan merupakan infrastruktur untuk merasakan dan mempengaruhi lingkungan fisik [2, 3].

Selain itu adanya penelitian yang menganalisis simulasi untuk membandingkan pada protocols HERA dan AODV [19], menunjukkan bahwa skema hirarkis routing yang berdasarkan MAC asosiasi prosedur menawarkan beberapa benefits dalam aplikasi jaringan sensor seperti:

a. ia mengeksploitasi informasi yang dipertukarkan selama jaringanpembentukan dan topologi fase update, sehingga menghindari tambahan routing pesan dan overhead yang terkait;

b. menunjukkan manfaat kinerja sehubungan dengan AODV, seperti berkurangnyaai latency dan konsumsi energi, dalam skenario aplikasi praktis;

c. mengurangi kompleksitas, karena sangat mudah untuk menerapkan dan tidak memerlukan daemon khusus pada perangkat host di mana ia berjalan.

Pada penelitian algoritmik (Ad-hoc On-demand Distance Vector, neuRFon) protokol-protokol yang dibuat untuk otomatisasi perancangan ad-hoc nodes jaringan berkecepatan rendah. Dalam kebanyakan kasus pada jaringan yang besar, jaringan akan menjadi sekelompok cluster. Hal ini juga dapat membentuk "mesh" atau "cluster tunggal". Profil dari mercusuar merupakan dukungan protokol ZigBee pada suar dan non suar yang ada yang di dapat jaringan. topik ini dalam rangka IEEE 802.15.4 standar.

Dalam non-suar yang didapat jaringan (yakni mercusuar yang ordernya 15), sebuah CSMA / CA mekanisme saluran akses yang digunakan adalah non-slotte. Dalam jaringan jenis ini, ZigBee Router biasanya memiliki receiver dan mereka terus aktif, membutuhkan catu daya lebih kuat. Namun, ini memungkinkan untuk jaringan heterogen di mana beberapa perangkat menerima terus menerus, sementara yang lain hanya mengirimkan ketika stimulus eksternal terdeteksi. Contoh khas dari sebuah jaringan heterogen adalah sebuah saklar lampu nirkabel: node ZigBee di lampu dapat menerima terus-menerus, karena terhubung ke suplai utama, sementara tombol lampu bertenaga baterai akan tetap tertidur sampai saklar dihidupkan. kemudian beralih mengirimkan perintah ke lampu, menerima sebuah pengakuan, dan kembali ke tidur. Dalam jaringan node lampu akan sekurangkurangnya Router ZigBee, jika tidak Koordinator ZigBee; ditukarnya tipe node saklar biasanya adalah alat terakhir dari ZigBee.

Dalam suar-jaringan yang didapat, node jaringan khusus yang disebut ZigBee Router mengirimkan suar periodik untuk mengkonfirmasi kehadiran mereka ke node jaringan lainnya. Node dapat tidur antara suar, sehingga menurunkan siklus tugas mereka dan memperpanjang hidup baterai mereka. interval suar dapat berkisar dari 15,36 milidetik untuk $15,36 \mathrm{~ms} * 214=251,65824$ detik pada 250 kbit / s, dari 24 milidetik hingga $24 \mathrm{~ms} * 214=$ 393,216 detik pada $40 \mathrm{kbit} / \mathrm{s}$ dan dari 48 milidetik hingga $48 \mathrm{~ms} * 214=786,432$ detik $20 \mathrm{kbit} / \mathrm{s}$. Namun, tugas siklus rendah dengan operasi interval mercusuar lama membutuhkan waktu yang tepat, yang dapat bertentangan dengan kebutuhan untuk biaya produk rendah.

Secara umum, protokol ZigBee meminimalkan waktu radio aktif sehingga mengurangi penggunaan daya. Dalam suar jaringan, node hanya perlu aktif saat mercusuar sedang dikirim. Dalam non-rambukemampuan jaringan, konsumsi daya jelas asimetris: beberapa perangkat yang selalu aktif, sementara yang lain menghabiskan sebagian besar waktu mereka tidur. Perangkat ZigBee yang diperlukan agar sesuai dengan IEEE 802.15.4-2003 Jaringan RendahTingkat Daerah Nirkabel Pribadi (WPAN) standar. Standar ini menentukan protokol lapisan bawahlapisan fisik (PHY), dan kontrol akses media (MAC) bagian dari lapisan data link (DLL). Standar ini menentukan operasi di 2,4 GHz tanpa izin, $915 \mathrm{MHz}$ dan $868 \mathrm{MHz}$ ISM band. Di band 2,4 GHz ZigBee ada 16 saluran, dengan saluran masing-masing membutuhkan $5 \mathrm{MHz}$ bandwidth. Pusat frekuensi untuk setiap saluran dapat dihitung sebagai, $\mathrm{FC}=$ 
$(2405+5 *(\mathrm{ch}-11)) \mathrm{MHz}$, di mana $\mathrm{ch}=11,12, \ldots$, 26.

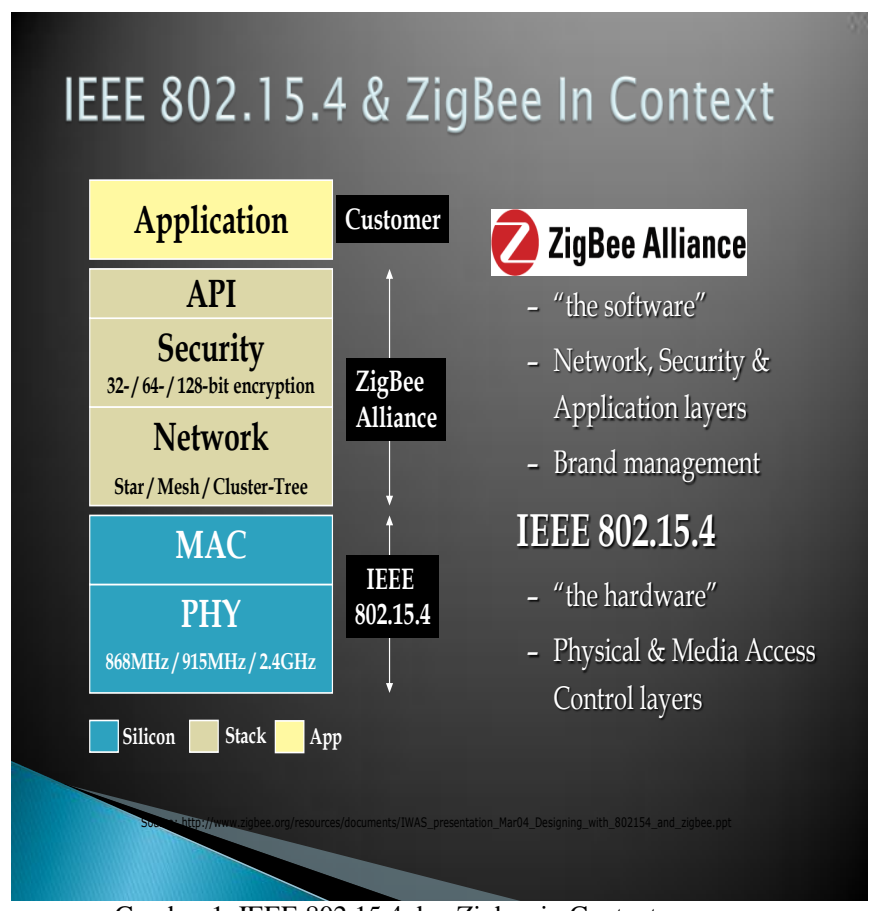

Gambar 1. IEEE 802.15.4 dan Zigbee in Context

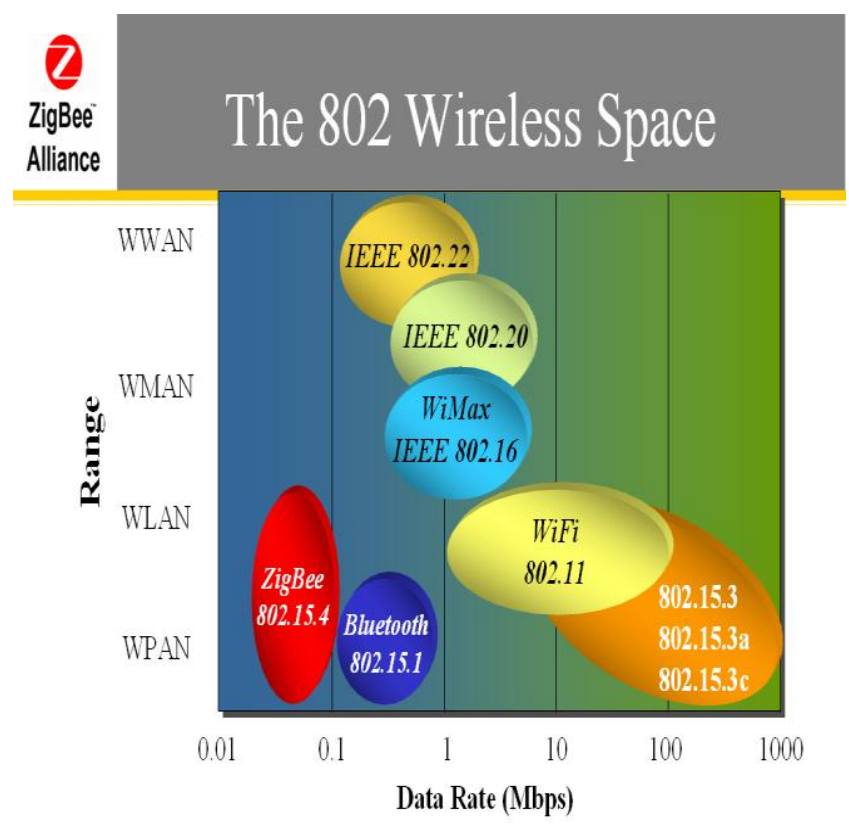

ZigBee" Alliance Irreless Control That Simply Work

Gambar 2. The 802 Wireless Space

Modus saluran dasar akses "pembawa arti, multiple access / menghindari tabrakan" (CSMA /
CA). Artinya, node berkomunikasi dengan cara yang sama bahwa orang berkomunikasi, mereka sebentar memeriksa untuk melihat bahwa tidak ada yang berbicara sebelum mereka mulai. Ada tiga pengecualian untuk penggunaan CSMA. suar dikirim pada jadwal waktu yang tetap, dan tidak menggunakan CSMA. Pesan pengakuan juga tidak menggunakan CSMA. Akhirnya, perangkat dalam jaringan suar berorientasi yang memiliki latency rendah persyaratan real-time juga dapat menggunakan Slot Waktu Dijamin (GTS), yang menurut definisi tidak menggunakan CSMA.

\subsection{Perangkat lunak dan perangkat keras pada ZigBee}

Perangkat lunak ini dirancang agar mudah untuk mengembangkan pada mikroprosesor mini dan murah. Desain radio yang digunakan oleh ZigBee telah dioptimalkan untuk biaya rendah dalam produksi skala besar. Ini memiliki beberapa tahap analog dan menggunakan sirkuit digital sedapat mungkin. Meskipun radio sendiri yang murah, Proses kualifikasi ZigBee melibatkan validasi penuh persyaratan lapisan fisik. Adanya sejumlah perhatian terhadap Physical Layer memiliki beberapa keuntungan, karena semua radio berasal dari yang ditetapkan topeng semikonduktor akan menikmati karakteristik RF yang sama. Di sisi lain, lapisan fisik uncertified yang malfungsi bisa melumpuhkan umur baterai perangkat lain pada jaringan ZigBee. Dimana protokol lain akan dapat sensitivitas yang buruk atau masalah esoteris lainnya dalam memudarnya kompensasi respon, radio ZigBee memiliki kendala teknik yang sangat ketat yakni: Power dan bandwidth dibatasi. Jadi, radio diuji dengan standar ISO 17025 dengan panduan yang diberikan oleh Pasal 6 dari Standard 802.15.4-2006. Kebanyakan vendor berencana untuk mengintegrasikan radio dan mikrokontroler ke sebuah chip tunggal.

Selain dukungan saat ini masih terdapat konroversi terhadap Zigbee. Sebuah kelompok penelitian akademis telah memeriksa alamat ZigBee pembentukan algoritma dalam spesifikasi 2006, dan berpendapat bahwa jaringan akan mengisolasi banyak unit yang dapat terhubung. Kelompok ini mengusulkan sebuah algoritma alternatif dengan kompleksitas yang sama dalam waktu dan ruang. Sebuah white paper oleh kelompok manufaktur Eropa (yang terkait dengan pengembangan standar bersaing, Z-Wave) mengklaim bahwa teknologi nirkabel seperti ZigBee, yang beroperasi di pita 2,4 $\mathrm{GHz} \mathrm{RF}$, yang mengalami gangguan signifikan cukup untuk membuat mereka tidak dapat digunakan. 
Klaim ini bahwa ini adalah karena adanya teknologi nirkabel lain seperti LAN Nirkabel di band RF yang sama. ZigBee Alliance merilis sebuah white paper menyangkal klaim ini. Setelah analisis teknis., makalah ini, menyimpulkan bahwa perangkat ZigBee terus berkomunikasi secara efektif dan kokoh bahkan di hadapan sejumlah besar gangguan

\section{KESIMPULAN}

Zigbee sebagai suatu spesifikasi untuk paket protokol komunikasi tingkat tinggi yang menggunakan sejumlah kecil radio digital daya rendah yang didasarkan pada, Standard IEEE 802.15.4 untuk jaringan nirkabel wilayah pribadi (WPANs) telah mengubah kemampuan alat-alat menjadi otomatis dapat di kaitkan (embedded) yang bekerja dengan sistem pada jaringan nirkabel. Secara

\section{REFERENSI}

[1] Wireless Medium Access Control (MAC) and Physical Layer (PHY) Specifications for Low Rate Wireless Personal Area Networks (WPANs),IEEE Std. 802.15.4, 2003.

[2] J. Zheng and M. J. Lee, "Will IEEE 802.15.4 make ubiquitous networking a reality: A discussion on a potential low power, low bit rate standard," IEEE Communications Magazine, vol. 27, no. 6, pp. 23-29, 2004.

[3] E. Callaway, P. Gorday, L. Hester, J. Gutierrez, M. Naeve, B. Heile, and V. Bahl, "Home networking with IEEE 802.15.4: a developing standard for low-rate wireless personal area networks," IEEE Communications Magazine, vol. 40, no. 8, pp. 70-77, Aug. 2002.

[4] "What is Zigbee". http://www.wisegeek.com/what-iszigbee.htm

[5]"ZigBee and Wireless Frequency Coexistence". zigbee.org. http://www.zigbee.org/imwp/download.asp?ContentID=11745. Retrieved on 2007-11-22.

[6] Adams, Jon; Bob Heile. "Busy as a ZigBee".IEEE. http://www.spectrum.ieee.org/oct06/4666. Retrieved on 200701-16.

[7]"Compare with Other Technologies". Bluetooth SIG. http://en.wikipedia.org/wiki/Wikipedia:Citation_templates. Ret retrieved on 2007-01-16.

[8]"Our Mission "zigbee.org.http://www.zigbee.org/en/about/. Retrieved on 2008-03-18.

[9]"ZigBee Specification Download Request". zigbee.org. http://www.zigbee.org/en/spec_download/download_request.a sp. Retrieved on 2008-03-18.

[10]Testa, Bridget (September 1, 2004). "ZigBee: Remote Control Euphoria". Telecommunications Online - Americas Edition. http://www.telecommagazine.com/Americas/article.asp?HH_I $\mathrm{D}=\mathrm{AR} \_601$. Retrieved on 2009-03-01.

[11]"ZigBee FAQ". http://www.meshnetics.com/zigbee-faq/. Retrieved on 2008-08-05.

[12]http://www.microcontroller.com/news/atmel_microcontrollers _avr.asp

[13] The Orphan Problem in Zigbee Wireless Networks

[14]"WLAN Interference to IEEE802.15.4". z-wavealliance.org. http://www.z-wavealliance.org/modules/iaCM-

DocMan/?docId=53\&mode=DE. Retrieved on 2007-11-22.

[15] Strassberg, Dan (4/13/2006). "Simple networks umum, protokol ZigBee meminimalkan waktu radio aktif sehingga mengurangi penggunaan daya.

Namun dibalik kesuksesan Zigbee sebagai teknologi nirkabel juga terdapat kontroversi, walaupun klaim kekurangan zigbee itu dapat di bantah oleh Zigbee Alliance dengan memberikan bantahan melaui white paper yang dirilisnya. Zigbee juga telah driilis untuk tujuan komersil dan juga non komersil, salah satu contoh pemanfaatan zigbee adalah headphone nirkabel menghubungkan dengan ponsel melalui jarak pendek radio. Ini adalah sebagai bukti cukup besar pemanfaatannya saat ini di bidang teknologi informasi dan komunikasi.Teknologi zigbee benar-benar telah merubah cara kerja di segala bidang menjadi lebih cepat dan lebih menghemat daya yang dihabiskan oleh suatu peralatan yang memanfaatkan teknologi zigbee.

will free many sensors from wires". .EDN. http://www.edn.com/article/CA6321525.html?industryid=2 814. Retrieved on 2009-03-01.

[16] Testa, Bridget (September 1, 2004). "ZigBee: Remote Control Euphoria". Telecommunications Online - Americas Edition. http://www.telecommagazine.com/Americas/article.asp?H H_ID=AR_601. Retrieved on 2009-03-01.

[17] "ZigBee FAQ". http://www.meshnetics.com/zigbee-faq/. Retrieved on 2008-08-05.

[18] "What is Zigbee". http://www.wisegeek.com/what-iszigbee.htm.

[19] Francesca Cuomo, Sara Della Luna, Ugo Monaco,and Tommaso Melodia. "Routing in ZigBee: benefits from exploiting the. IEEE 802.15 .4 association tree", IEEE Communications Society in the ICC 2007 proceedings 